\begin{tabular}{c} 
International Journal of Engineering \& Technology, $7(4.34)(2018)$ 336-339 \\
International Journal of Engineering \& Technology \\
SPC \\
Website: www.sciencepubco.com/index.php/IJET \\
Research pa \\
\hline
\end{tabular}

\title{
Enterprise Architecture Model for a Rural Healthcare Service Facility in Java Indonesia
}

\author{
Sri Lestari ${ }^{1 *}$, Novy Mustikawati ${ }^{1}$, Samsul Bahri $^{2}$ \\ ${ }^{1}$ Information System, Faculty of Engineering, Widyatama University, Indonesia \\ ${ }^{2}$ FKIP, Wiralodra University, Indonesia \\ *Corresponding author E-mail: sri.lestari@widyatama.ac.id
}

\begin{abstract}
The purpose of the enterprise architecture design is to align Technology Information with business for fulfilling the needs of the organization in the rural healthcare service facility sector. In this research, Enterprise Architecture design use Framework TOGAF Architecture Development Method. The research is focused in the rural healthcare service facility in Bandung, Indramayu and Brebes cities in Java Indonesia. The results provide enterprise architecture model for a rural healthcare service facility in Java Indonesia. This study is perhaps one of the first model for rural healthcare service facility in Java Indonesia.
\end{abstract}

Keywords: Rural Healthcare Service; Enterprise Architecture; TOGAF Architecture Development Method; Java; Indonesia.

\section{Introduction}

Some of the challenges rural quality improvement efforts face, identified in a 2015 National Quality Forum (NQF) report, Performance Measurement for Rural Low-Volume Providers include lack of information technology [4].

Rural Healthcare service facility today are driven by competition to improve the quality of their services by utilizing information systems with its technology. However, the implementation of information systems usually is focusing on momentary needs and causing the application of information systems to be overlapping. The result of this condition is that the information systems cannot be utilized in accordance with the mission and goals of the organization [6].

The above problems are caused by several factors. One of them is the lack of planning and ignoring the main keys in the development process of information systems. The process of designing information systems has to be conducted through several stages. The design stages start with defining the business architecture of the rural healthcare service facility and following by the data architecture to be used. The next steps are building the application and technology architecture that will support the operational of the information systems. The process of alignment of all factors in information systems implementation can be fulfilled by paying attention to the integration factors in its development. Enterprise architecture is one of the tools that can be used to reduce the gap in the system development process by align all of the key factors in information systems development [2].

\section{Literature Review}

There are some prominent enterprises architecture methods and frameworks such as the Zachman, EAP, Framework, EAS, BEAM, GEAF, and TOGAF ADM [1]. Previous studies showed that TOGAF ADM is a complex method, however, it is capable to fulfill all of Enterprise Architecture development needs by $92 \%$ [6].

TOGAF ADM can be adapted to certain specific needs, for example, TOGAF ADM can be combined with other frameworks to produce an organization-specific architecture [7].

TOGAF ADM is also flexible to be combined with other frameworks such as the Zachman framework or FEAF [8].

\section{Theoretical Framework}

Enterprise architecture is a way to describe an enterprise operational model that includes aspects of business planning, business operations, automation, and supporting information technology infrastructure [6].

The core of ADM is the management of needs, where business needs, information systems, and technology architectures are always aligned with business goals and needs [6].

TOGAF is an architectural framework. TOGAF provides tools and methods to help reception, production, use and maintenance of enterprise architecture. It is based on an iterative process model supported by best practices and a reusable set of architectural assets [5]. 


\section{Methodology}

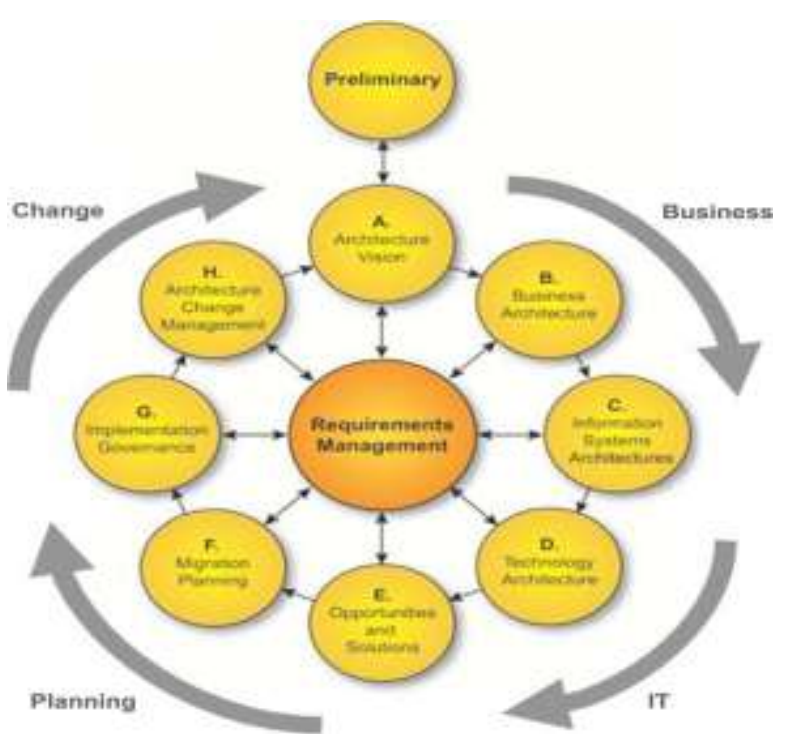

Fig. 1: TOGAF Architecture Development Method [5]

Business process describes a set of activities that occur in an organization. Business process that exist in rural healthcare service facility are:

a. Patient Health Service Process

b. Patient Registration Process

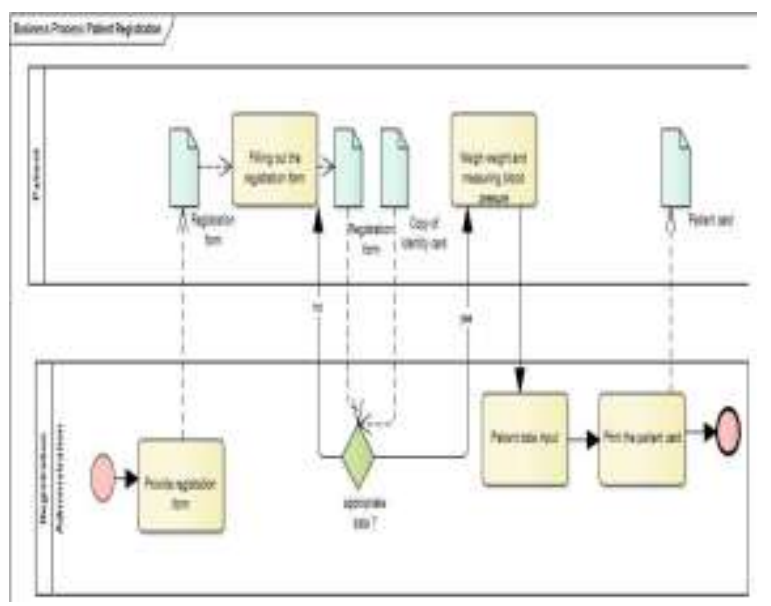

Fig. 2: Patient Registration Process

The process of registering new patients in rural healthcare service facility can be done by way of the patients came directly to rural healthcare and registration directly to the Administration section [3].

c. Service Process / Outpatient Examination

d. Laboratory examination

e. Service Process / Inpatient Patient Inspection

f. Drug Taking Process

g. Patient Billing Payment Process

h. Non-Medical Medical Supplies Inventory Management Process

i. Drug Inventory Management Process

j. Employee Acceptance Process

k. Employee Payroll Process

\section{Enterprise Architecture Planning}

\subsection{Preliminary Phase}

Principle catalogs at the rural healthcare are as follows.
Table 1: Principle Catalog

\begin{tabular}{|c|c|}
\hline \\
\hline Categories of Principles & Principles \\
\hline \multirow[t]{7}{*}{ Business Principles } & Primary of Principles \\
\hline & Maximize Benefit to the Enterprise \\
\hline & $\begin{array}{l}\text { Information Management is Everybody's } \\
\text { Business }\end{array}$ \\
\hline & Business Continuity \\
\hline & Compliance with Law \\
\hline & IT Responsibility \\
\hline & Protection of Intellectual Property \\
\hline \multirow[t]{6}{*}{ Data Principles } & Data is an Asset \\
\hline & Data is Shared \\
\hline & Data is Accessible \\
\hline & Data Trustee \\
\hline & Common Vocabulary and Data Definitions \\
\hline & Data Security \\
\hline \multirow[t]{2}{*}{ Application Principles } & Technology Independence \\
\hline & Ease-of-Use \\
\hline \multirow[t]{3}{*}{ Technology Principles } & Requirements-Based Change \\
\hline & Responsive Change Management \\
\hline & Interoperability \\
\hline
\end{tabular}

These principles are used as a reference in architectural decision making in the field of information systems and information technology. Principle catalog in the table above consists of four categories of principles namely business principles, data principles, application principles and technology principles. The four groups of principles are then broken down into principles.

\subsection{Phase A: Architecture Vision}

Solution Concept Diagram at the rural health care is as follows.

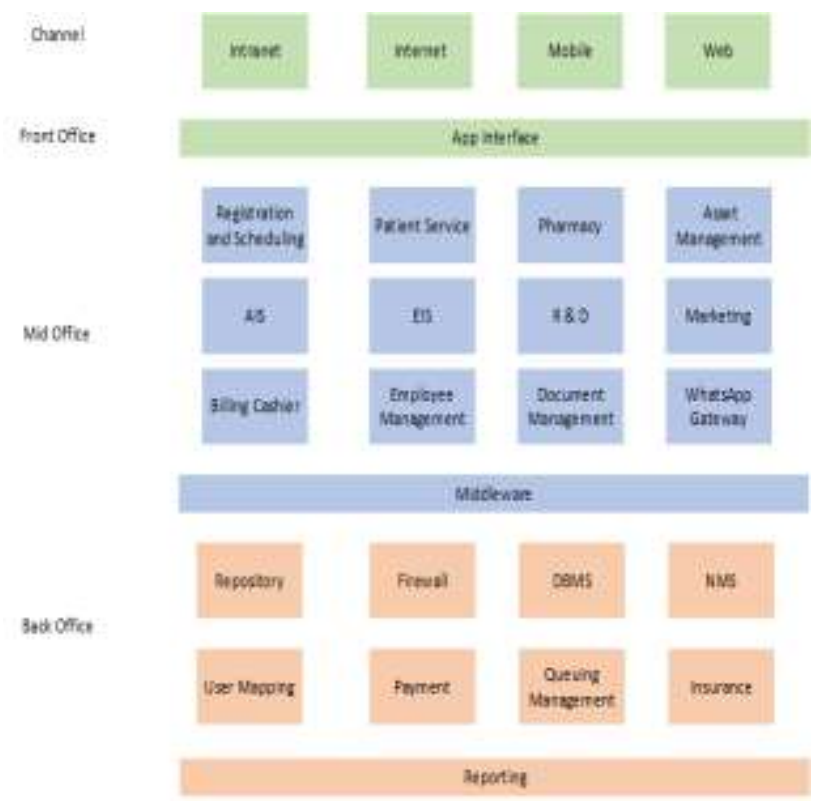

Fig. 3: Solution Concept Diagram

Solution Concept Diagram is a description of the concept of the proposal that will be applied. Solution Concept Diagram consists of four layers namely channel, front office, mid office, and back office. Channel shows how users access the front office via intranet, internet, mobile and the web. Mid office is a part that support the business activities of companies such as registration and scheduling, patient services, accounting information systems, personnel and others needed to implement Clinical Information Systems. Back office has a monitoring function and process data into reporting.

\subsection{Phase B: Business Architecture}

Process Flow Diagram

In this section will describe how business processes after applied clinical information system later. 
a. Patient Health Service Process

b. Patient Registration Process

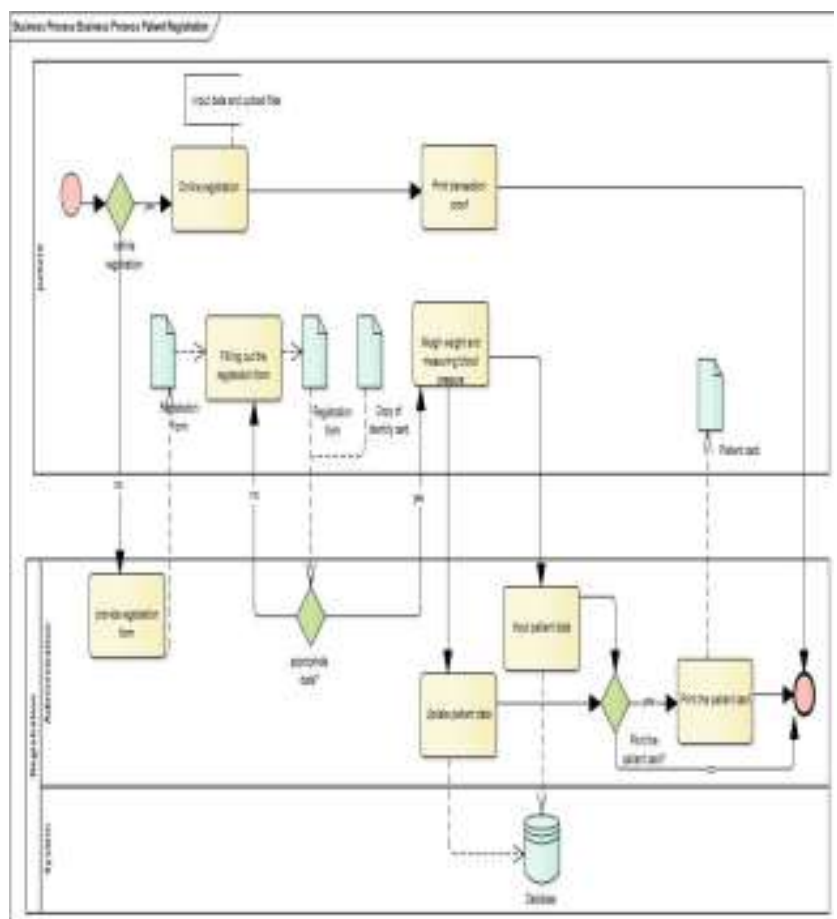

Fig. 4: Patient Registration Process

There is a difference in the registration process, in the existing process, patients can only register by coming directly to the clinic, while for the proposed process the patient can register online via web or mobile application. But, if the patient does not register online, patients can directly register at the clinic. Online registration is done by the patient inputting the data and uploading the necessary files such as the ID card scan, then the result of the transaction is printed as proof that the patient has registered.

c. Service Process / Outpatient Examination

d. Laboratory examination

e. Service Process / Inpatient Patient Inspection

f. Drug Taking Process

g. Patient Billing Payment Process

h. Non-Medical Medical Supplies Inventory Management Process

i. Drug Inventory Management Process

j. Employee Acceptance Process

k. Employee Payroll Process

1. Alert System

\subsection{Phase C: Information System Architecture}

Class diagrams in the rural health care as follows

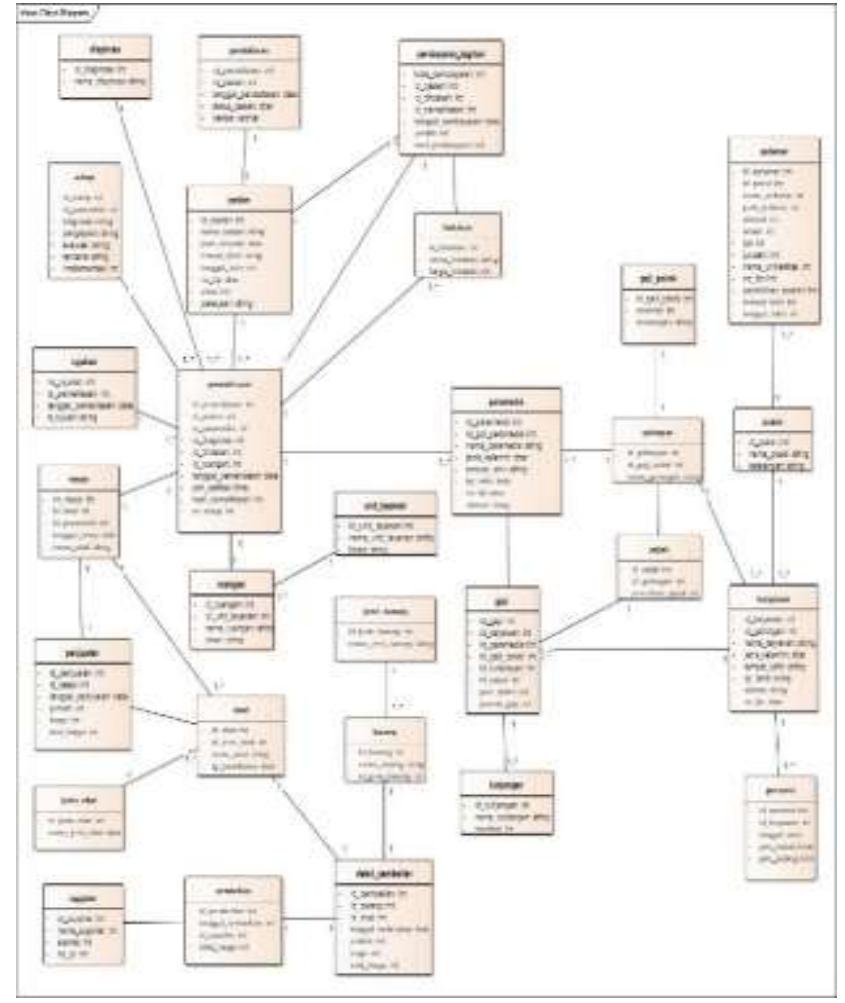

Fig. 5: Class Diagram

Class diagrams are used to show relationships between entities and their attributes. In the diagram above shows that there are 29 entities that have their respective attributes and relate with other entities and also showed its cardinality. Existing entities include the patient entity, examination, room, diagnosis, payment, etc.

\subsection{Phase D: Technology Architecture}

The following are the communication engineering diagrams are proposed.

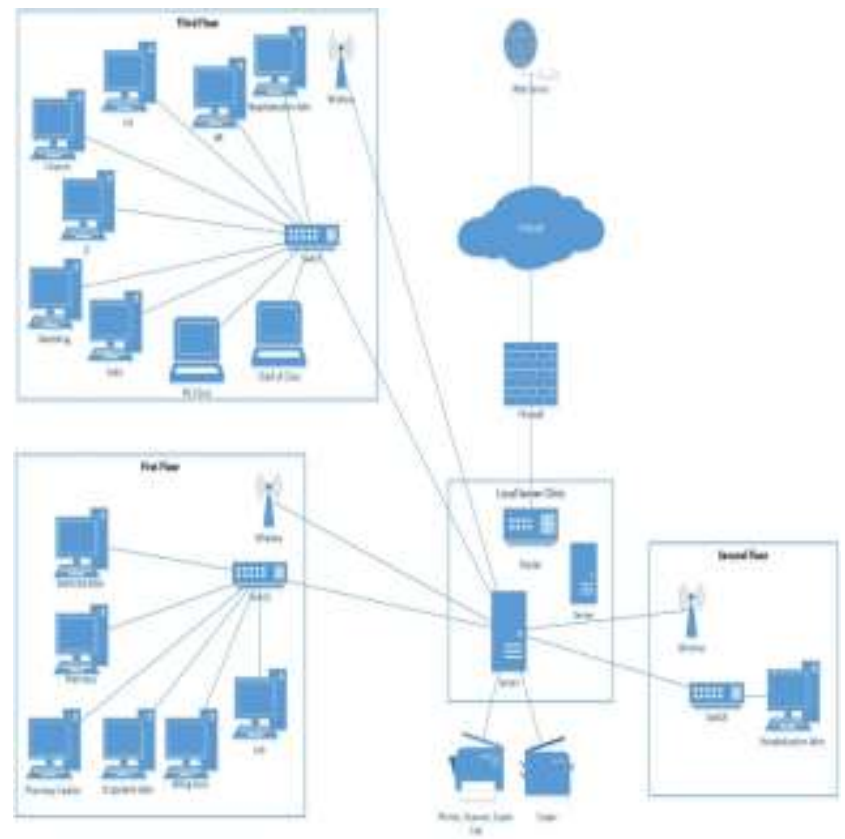

Fig. 6: Communication Engineering Diagram

This diagram is used to describe the proposed network architecture in the creation of enterprise architecture at rural health care. In the picture shown that the rural healthcare is a 3 -storey building with each section on each floor having a PC. Then, each floor has a switch and wireless that connects each part to the server. 


\subsection{Phase E: Opportunities and Solution}

The Benefit Diagram shows the opportunities identified in the architecture definition. In the picture above there are three groups, for the first group (located on the left) shows details of benefits that will be felt the rural healthcare service facility later. Details in the first group are then grouped into three categories: improved service quality, improved effectiveness of inventory management and improved effectiveness of employee data management. Then, the third group is the main benefits that are expected to be obtained rural healthcare that is the efficiency of service and improvement of rural healthcare performance.

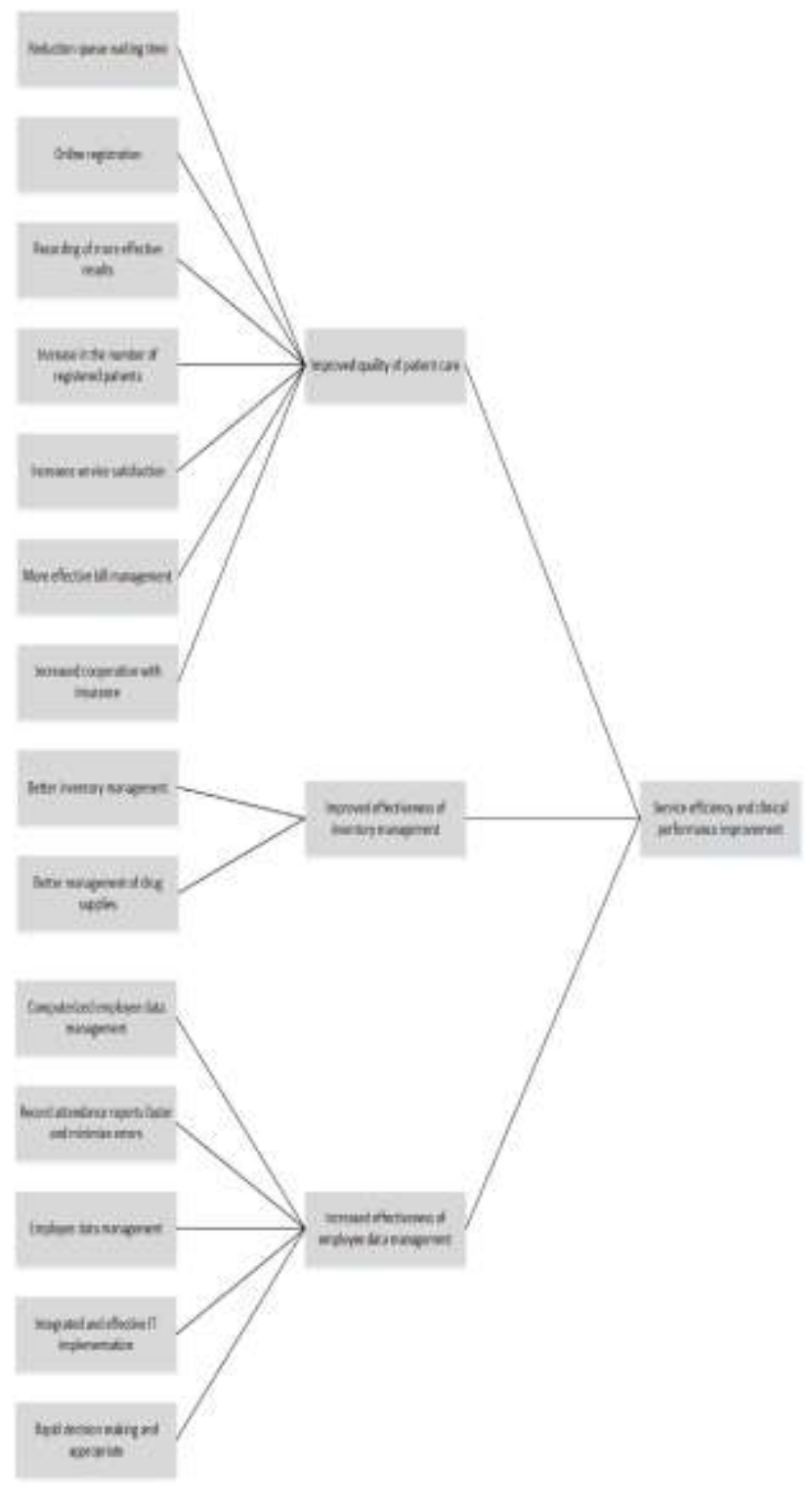

Fig. 7: Benefit Diagram

\section{Discussion and Conclusion}

Based on the results of observations and analysis obtained in this study illustrates that rural healthcare service facility does not have an integrated system that cannot be used to help maximize operational activities. Therefore, this research makes an enterprise architecture design to maximize the use of information system with technology information so that the existing system in the rural healthcare can be integrated well so that it can assist healthcare operational activities.

This design resulted in the enterprise architecture model using the TOGAF ADM framework in order to align the business strategy and the information system with technology information strategy to support the existing business activities in the rural healthcare service facility. Enterprise architecture planning is a blueprint of the main architecture on TOGAF, which is business architecture, application architecture, data architecture and technology architecture.

\section{References}

[1] Budi SE. (2009). Selection of EA Framework. Prosiding SNATI, (UII, Yogjakarta) B114-B119.

[2] Falahah RD. (2010). Implementation of the Zachman Framework on managing operational data, Prosiding SNATI, (UII, Yogjakarta) A96-A98.

[3] Muula AS. (2007). How do we define "rurality" in the teaching on medical geography? Rural Remote Health.

[4] National Quality Forum (NQF) report. (2015). Performance Measurement for Rural Low-Volume Providers.

[5] The Open Group. (2012). Open Group Standard TOGAF Version 9.1. The Open Group.

[6] Yunis R, Surendro K, Panjaitan E. (2009). Utilization TOGAF ADM for Enterprise Architecture Model Design. Jurnal Ilmiah Informatika Komputer, 14(2),

[7] Setiawan EB. (2009). Pemilihan EA framework. Proceedings of the Seminar Nasional Aplikasi Teknologi Informasi, pp. 114-119.

[8] Paszkiewicz Z, Picard W. (2010). MAPSS, a multi-aspect partner and service selection method. Proceedings of the Working Conference on Virtual Enterprises, pp. 329-337. 